\title{
Extending the Extended Family for Homeless and Marginally Housed African American Women
}

\author{
Cheryl M. Killion, Ph.D., R.N.
}

\begin{abstract}
Young homeless African American women and elderly marginally housed African American women have health, housing, and personal concerns specific to their age cohort, yet they also have parallel and complementary needs. The young struggle to find affordable housing, while the old may have difficulty in maintaining their homes. This article reports select findings from a pilot study designed to describe these two groups of women. The preliminary study was conducted preparatory to the development of a larger study to explore factors that would facilitate or hinder linking the two groups of women for mutual assistance in housesharing arrangements. Interviews and housing history findings revealed contrasts and similarities among the women and between both cohorts that reflected individual differences, common yet divergent life courses, and collective responses to family life situations, societal trends, and policies. Advantages and disadvantages of housesharing were delineated with $56.3 \%$ of the homeless women and $81.3 \%$ of the elderly women viewing coresidential living as an option worth considering. Housesharing arrangements should be further investigated by nurses and colleagues. Findings from this study are foundational for establishing alliances that may be a means to promote health and strengthen "family" in both populations.
\end{abstract}

Key words: African American women, housing, homelessness, extended family, poverty, generations, housesharing, women's health.

Cheryl M. Killion is an Assistant Professor, School of Nursing, University of Michigan, Ann Arbor, Michigan.

Address correspondence to Cheryl M. Killion, School of Nursing, University of Michigan, $400 \mathrm{~N}$. Ingalls, Ann Arbor, MI 48109-0482. E-mail: ckillion@umich.edu

\section{INTRODUCTION}

Historically, the extended family has been a primary source of strength, sustenance, and survival in the African American community. By nature it is multigenerational, interdependent, highly interactive, often extends beyond household boundaries, frequently includes nonrelatives, and provides material aid and moral and emotional support for its members (Hatchett, Cochran, \& Jackson, 1991; Stack, 1974). In 1975, one in five African Americans lived within an extended household (Hatchett et al., 1991). Today, however, greater numbers of single families and individuals are living in isolated households and are not linking with or being absorbed by their family of origin or extended kin (Hatchett et al., 1991; "The State of the Nation's Housing," 1998). Moreover, it is increasingly the case that young African American families, particularly those headed by women, are periodically without a permanent, stable home, and elderly African American women are disproportionately among those who are marginally housed.

Families are the fastest growing segment of the homeless population (Jahiel, 1992; Mills \& Ota, 1989; Stark, 1992). Homeless families comprise approximately $40 \%$ of the homeless population (U.S. Conference of Mayors, 1993). Most of the heads of households of these families are women, between the ages of 20 and 35 years, who have minimal social support from friends and family. These women also typically lack vocational training, job experience, and child care, and have little knowledge about how to navigate the health care system and social service agencies (Killion, 1988, 1995, 1998; Stark, 1992). Although shelters have proliferated and services have been developed to ad- 
dress the needs of this burgeoning group, the cycle of homelessness remains unbroken for most. Inadequate housing has a tremendously negative impact on the quality of life of these families and can have devastating effects on their health. Moreover, the developmental impact of homelessness on children is pervasive, severe, and cumulative (Harrison, Wilson, Pine, Chan, \& Buriel, 1990; Wagner \& Menke, 1992).

By comparison, the elderly have been less affected by the housing crisis than other segments of the population. Since 1970, changes in Social Security have lifted many of this age group out of poverty (Heclo, 1988). Two thirds of the elderly own their homes ("The State of the Nation's Housing," 1998). The few extant studies about the housing situation of the elderly who rent and own, however, reveal that as the elderly population increases, the amount of available low-income housing declines (Mank \& Kaye, 1991). In fact, the homeless elderly are relatively invisible, and a number of domiciled elderly live in deplorable conditions (Rich, 1995). In addition, the elderly are at risk for multiple resource deficits, which are clearly precursors of losing their homes. For some, the loss of mental and physical capacity is the most salient factor contributing to the inability to maintain their surroundings. Loss of income, loss of financially supportive persons to share household expenses, and evictions, however, are the clearest antecedents of homelessness (Mank \& Kaye, 1991; Rich, 1995). Despite deteriorating neighborhoods, a significant number of the elderly prefer to remain in their homes, among familiar surroundings, and to "age in place" (Mank \& Kaye, 1991; "Preventing Homelessness," 1991; "The State of the Nation's Housing," 1998).

Ethnicity and gender further complicate the housing situation of both young families and the elderly. The number of homeless among African Americans is particularly high (Hopper \& Milburn, 1996; Barrow, Herman, Cordova, \& Struening, 1999). The disproportionate number of homeless African Americans is consistent with the long history of discrimination in housing and employment and the concomitant number of individuals and families living below the poverty line. During the last decade, there were significant increases in the number of female-headed households and the number of households in which the elderly and young, mostly female, reside alone (Hatchett et al., 1991; Leigh, 1992; Levinson, 1991).

Poor, marginally housed, elderly African American women and unhoused, young African American women have health, housing, and personal concerns specific to their age cohorts, yet they also have parallel and complementary needs. The young struggle to find affordable, decent housing, while the old may have difficulty maintaining their homes. This article reports select findings from a pilot study designed to describe these two cohorts of poor women. The preliminary study was conducted preparatory to the development of a larger study to explore factors that would facilitate or hinder linking the two groups of women for mutual assistance in housesharing arrangements. Housesharing is a living situation in which two or more unrelated adults share a residence for their reciprocal advantage (Levinson, 1991; Mantel \& Gildea, 1989).

\section{METHODS}

This study was conducted in a Midwestern city characterized by a cyclical economy based primarily on the automobile industry. The per capita income of the city's African American population was $\$ 9,474$, one half of the per capita income of the general population of the United States (U.S. Bureau of the Census, 1990). The convenience/quota sample (Patton, 1990; Bernard, 1994) consisted of 16 homeless women recruited from a large family shelter and 16 women aged 65 years and over, who were recruited from the city's Agency on Aging. These women lived alone in their own apartments or houses.

All procedures were approved by the respective institutional review boards for human subjects. The researchers obtained informed consent from the participants, and then conducted face-to-face, semistructured interviews and housing histories. Prior to administering the protocols, content validity and test-retest reliability of the instruments were established.

The interviews elicited demographic information, general health data, current housing and health related needs, concerns, and preferences. The questionnaires for both cohorts of women were essentially the same, although the interview schedules were slightly different to appropriately capture the specifics of their respective daily life experiences. The housing history included questions that elicited information about the women's current and past residences and neighborhoods. The interviews and housing histories, which took approximately 90 minutes to administer, were tape recorded and transcribed verbatim. Trained interviewers conducted interviews of the homeless women in a private office in the shelter. The elderly women were interviewed in their homes. Semantic content analysis (Weber, 1995) was used to categorize the narrative responses and identify themes from the interviews. Descriptive statistics were used to summarize quantifiable responses.

\section{RESULTS}

Interviews and housing history findings are combined and reveal contrasts and similarities among the women and between both cohorts that reflect individual differences, common yet divergent life courses, and collective responses to family life situations, societal trends, and policies. 


\section{Demographic Profiles of the Women}

All of the women were lower socioeconomic African American women (Table 1). Their ages ranged from 19 to 41 years (mean age: 29 years) in the younger women and 65 to 81 years (mean age: 69 years) in the elderly women. Over $90 \%$ of the younger women were single and had never been married. All of the elderly women, except one, had been married, however, three were divorced or separated and the remainder were widowed. Educational levels for both groups of women were relatively low. Three women $(18.8 \%)$ of each group had received less than 11 years of education, though $75 \%$ had received a diploma for completing high school or had passed a high school equivalency test. Two of the homeless women reported having graduated from vocational/trade school or community college. All of the women who resided in the shelter were currently unemployed. The women from both age cohorts had held low wage, minimal benefit jobs such as fast food or domestic workers, childcare or nurse's aides, car wash attendants, factory workers, or cosmetologist aides. One of the elderly women, however, had been an office supervisor and another had been an intake officer for a service agency. The primary source of income for the younger women was public assistance, though in addition, three women $(18.8 \%)$ received some help from family members or boyfriends. The majority of the elderly women were retired and relied primarily upon social security. In addition, three $(18.8 \%)$ of the women had pensions and three (18.8\%) supplemented their income with earnings from part-time employment. Medicaid and Medicare were the primary health insurance options for the women. Fourteen of the 16 younger homeless women and 12 of the domiciled women over 65 were Protestant. Three of the homeless women indicated that they rarely engaged in religious or spiritual activity, however, four of the women engaged in some type of spiritual activities at least once a week. Six of the older women engaged in some type of religious activity everyday. All of the women used the bus as their primary source of transportation.

TABLE 1. Demographic Characteristics of the Sample

\begin{tabular}{|c|c|c|c|c|c|c|c|c|}
\hline \multirow[b]{2}{*}{ Characteristic } & \multicolumn{4}{|c|}{ Young and Homeless Women } & \multicolumn{4}{|c|}{ Elderly Marginally Housed Women } \\
\hline & & $n$ & $\%$ & Mean & & $n$ & $\%$ & Mean \\
\hline & & 16 & & & & 16 & & \\
\hline Age & Range & $19-41$ & & 29 & Range & $65-81$ & & 69 \\
\hline \multicolumn{9}{|l|}{ Marital status } \\
\hline Single & & 15 & 93.8 & & & 1 & 6.2 & \\
\hline Divorced & & 1 & 6.2 & & & 2 & 12.5 & \\
\hline Separated & & 0 & & & & 1 & 6.2 & \\
\hline Widowed & & 0 & & & & 12 & 75.0 & \\
\hline Married & & 0 & & & & 0 & & \\
\hline \multicolumn{9}{|l|}{ Educational level } \\
\hline 11th grade or less & & 3 & 18.8 & & & 3 & 18.8 & \\
\hline High school grad or equivalent & & 11 & 68.7 & & & 13 & 81.3 & \\
\hline Vocational/trade school & & 1 & 6.2 & & & 0 & & \\
\hline Some college & & 1 & 6.2 & & & 0 & & \\
\hline \multicolumn{9}{|l|}{ Primary source of income } \\
\hline AFDC* & & 16 & 100.0 & & & 0 & 100.0 & \\
\hline Social security & & 0 & & & & 16 & & \\
\hline \multicolumn{9}{|l|}{ Primary health insurance } \\
\hline Medicaid & & 15 & 93.8 & & & 3 & 18.8 & \\
\hline Medicare & & 0 & 6.2 & & & 13 & 81.2 & \\
\hline Other & & 1 & 6.2 & & & & & \\
\hline \multicolumn{9}{|l|}{ Major type of transportation } \\
\hline Bus & & 16 & 100.0 & & & 16 & 100.0 & \\
\hline Car (owned) & & 0 & 0.0 & & & 0 & 0.0 & \\
\hline \multicolumn{9}{|l|}{ Religious affiliation } \\
\hline Protestant & & 14 & 87.5 & & & 12 & 75.0 & \\
\hline Islamic & & 1 & 6.2 & & & 0 & & \\
\hline Other & & 0 & 0.0 & & & 4 & 25.0 & \\
\hline No affiliation & & 1 & 6.2 & & & 0 & & \\
\hline
\end{tabular}

*AFDC has been replaced by TANF (Temporary Assistance to Needy Families). 


\section{Housing Histories}

The residential patterns of the two groups of women were remarkably different from each other. The younger homeless women had moved numerous times during their lifetime (range, 5 to 15 times or more). During the 5 years preceding the time they were interviewed for the study, three women responded that they had moved, "too many times to count." The other 13 women had moved 3 to 6 times within the most recent 5 years. Fifteen of the 16 homeless women were born and had grown up in the metropolitan area where the pilot study took place. In contrast, all but one of the elderly women had moved to the area from the South during their early adulthood. They were part of a mass migration of Blacks who had moved to the North to secure jobs (or for their spouses to secure jobs) in industry. The maximum number of times the elderly women had moved during their lifetime was 9 , but the average was 5 times. Reasons for moving varied between the two groups. The elderly women moved primarily to seek better opportunities for themselves and their families. They also desired more or less space depending on their life phase. The homeless women usually moved because of some adverse situation such as family conflict, domestic violence, or eviction for inability to pay rent. Women from both cohorts experienced major life events or societal changes that affected housing while they lived at particular residences that also influenced their decisions to move: death of a family member, divorce, substance use, breadwinner's loss of job, a family member becoming disabled, or demolition of housing units.

\section{Perceptions of Home}

The women were asked three questions about their current residence: (1) Do you consider where you are currently staying to be your home? (2) Do you consider home and house to be the same thing? (3) What features are important to have in an apartment or house that make it a home? Fifteen $(93.8 \%)$ of the elderly women viewed their current residence as their home. Nine $(56.3 \%)$ of the homeless women viewed the shelter as their home, "I know where I'm going to sleep tonight-to me that's home." Fifty percent of the women in both cohorts viewed "house" and "home" to be synonymous. The women in both age groups had similar perceptions of what makes a home. Common responses were "love," "God," "peace," "having paid for the residence," "a place to eat and sleep," "comfort," and a "place where you can relax." Differences between the two groups of women reflected priorities specific to their particular age cohort and particular life circumstances. For example, the women in the older age cohort desired a place that was convenient. They preferred a home that was centrally located and had features that made daily living comfortable and easy to manage. The older women also felt that home meant being near family, friends, and loved ones. For the homeless women, "home" meant having privacy, safety, cleanliness, and their own possessions.

Although the older women overwhelmingly viewed their current residence as "home," they expressed dissatisfaction in several areas. Women who lived in regular or subsidized apartments for the elderly were dissatisfied with not having some of the features they had had in their previous residence. The most frequent complaints were about limited space, lack of yards, inability to move about freely, and few options to decorate and personalize their places. The women who resided in a house that they owned were concerned about deterioration of the neighborhood and two of the women had problems with upkeep of their homes and property.

\section{Social Support}

In an effort to ascertain minimal levels of social support, the women were asked who they would call in an emergency and who took care of them when they were ill. When one homeless woman was asked who she would call in an emergency, her immediate response was "God." This response conveyed some notion of her spiritual grounding and coping strategies, yet other related responses revealed that she also was hard pressed to name an individual whom she could call on and actually get help. Fourteen (87.5\%) of the homeless women would call upon a relative (someone from their family of origin). Fifty percent of that number would call their mother. Two of the women would call a friend. Twenty-five percent of the elderly women would call one of their children. Although their contacts were limited, the women over 65 years had a larger network than their younger cohorts, including siblings, other relatives, their minister, neighbors, "numerous people," and the police.

Similar patterns emerged when the women were asked who took care of them when they became ill. Twelve (75\%) of the 16 homeless women indicated that they took care of themselves when they became ill. One reported that her children were her primary caregivers. Another stated that her ex-partner took care of her, and still another indicated that a relative was the one she could count on. In contrast, the elderly women relied upon their grown children, other relatives, or friends to take care of them. Twenty-five percent of the elderly women stated that they took care of themselves when they became ill. One woman in each of the groups denied ever becoming ill.

\section{Health Status}

When the homeless women rated their health, none of them indicated that they had excellent health, but only one rated 
her health as being poor. Ten of the women reported that their health was good. An average rating was given by four women. As for the women 65 years and older, $25 \%$ responded that they were in excellent health and 25\% felt that they were in poor health. Six of the women (37.4\%) rated their health as good and two (12.7\%) rated their health as average. Women from both groups gave similar responses as to how they stayed healthy. Common responses included eating properly, exercising, and abstaining from drinking, drugs, and smoking. One woman from each age group indicated that she "did nothing" to stay healthy.

\section{Coresidential Preferences}

The extent to which the women would be willing to consider coresiding with a nonrelative varied by age group. Thirteen $(81.2 \%)$ of the elderly women stated that they would be willing to live with someone they did not know well, provided that the individual was properly screened. On the other hand, nine $(56.3 \%)$ of the homeless women stated that they would be willing to houseshare. The women were asked to rank their preferences as far as a prospective housesharing partner (Table 2). The options the women were given in the interview were: (1) a woman 18 to 35 years with no children; (2) a woman 18 to 35 years with two children or less; (3) a man 18 to 35 years with no children; (4) a man 18 to 35 years with two children or less; (5) a woman over 65 years and (6) a man over 65 years. Both cohorts of women selected women near their same age cohort with no children as their first choice. Interestingly, the elderly women's second choice was a younger woman with two children or less. For the homeless women, their second choice was a women over 65 years. Living with a man (with no children) received their third highest ranking.

The domiciled and undomiciled women gave similar responses as to why they would be willing to houseshare. The women desired companionship and the opportunity to share expenses and tasks:

I would enjoy the conversation-having someone around to talk to. We could become friends.

It would have to be a younger man. He could help fix things when they needed it . . . . I would feel much safer with a man in the house. (-Older woman)

Beyond the obvious reasons for desiring a coresidential arrangement, the women indicated that a house partner could be like family or kin.

My grandkids are miles away, so I would love having children around, if they minded.

It would be kind of nice to live with someone, say, who could be a grandmother for my kids - and even a mother to me. My mother died when I was five so that's something I've always missed. (-Younger woman)

My home would be her home.

Reasons for not wanting to houseshare varied across groups. The three $(18.8 \%)$ elderly women who were not willing to contemplate a coresidential arrangement yearned for privacy. "I might want to walk around in my nightshirt or something. Can't do it if someone's there." There were other concerns about safety. "I can live alone and be afraid of the hoodlums, or I can take in someone I don't know and be afraid of the one I've taken in and the hoodlums." The undomiciled women were also concerned about privacy issues and losing some of their independence. Women who had come to the shelter as a result of domestic violence were particularly concerned about the welfare of their children. Two younger women were afraid about the possibility of a male house partner abusing their children. The women

TABLE 2. Coresidential Preferences*

\begin{tabular}{|c|c|c|c|c|}
\hline \multirow[b]{2}{*}{ Options for Coresidential Preferences } & \multicolumn{2}{|c|}{$\begin{array}{c}\text { Younger Homeless } \\
\text { Women } \\
n=15^{* *}\end{array}$} & \multicolumn{2}{|c|}{$\begin{array}{c}\text { Elderly Marginally } \\
\text { Housed Women } \\
n=16\end{array}$} \\
\hline & \# & $\%$ & \# & $\%$ \\
\hline Woman, 18 to 35 years, no children & 5 & 33.3 & 1 & 6.2 \\
\hline Woman, 18 to 35 years, 2 children or less & 3 & 20.0 & 4 & 25.0 \\
\hline Man, 18 to 35 years, no children & 2 & 13.3 & 3 & 18.8 \\
\hline Man, 18 to 35 years, 2 children or less & 1 & 6.7 & 0 & 0.0 \\
\hline Elderly woman 65 years and over & 4 & 26.7 & 8 & 50.0 \\
\hline Elderly man 65 years and over & 0 & 0.0 & 0 & 0.0 \\
\hline
\end{tabular}

*The women were asked to rank their choices even if they would not entertain housesharing as an option.

** One woman refused to rank her choices. 
were also adamant about being in a doubling up situation whereby conflicts and dissension might occur.

\section{DISCUSSION}

The study's findings provide a foundation for understanding some of the health and housing needs and preferences of two generations of lower socioeconomic, African American women. Baseline data suggest that the potential exists for a reciprocal living relationship between the two cohorts of women.

The sociodemographics of the homeless, younger women and the older marginally housed women reflect distinct yet common, coexisting patterns. Generations separate the women, but the early and later effects of their low educational attainment; low status, low wage, no benefit jobs; single marital/single parental status; and poor housing conditions, all confounded by their ethnicity and gender, portray a continuum of "cumulative disadvantage" (Crystal \& Shea, 1990; Crystal, Shea, \& Krishnaswami, 1992). For both cohorts of women, this profile mirrors the path that has been consistently reported in the literature. For example, an association between education and economic well-being is well documented (Crystal et al., 1992). Those with less education are likely to have access primarily to low status jobs, are less likely to be self-employed, and are more likely to have a limited or disrupted work history (Select Committee on Aging, House of Representatives, 1989). This is particularly true of women, as they are usually the primary caregivers of the young, sick, and older family members. In addition, individuals with lower levels of education are less likely to save their earnings and tend to have limited or no fringe benefits from their jobs (Solmon, 1975; Barusch, 1994). Similarly, low educational attainment and low-income status have been demonstrated to adversely effect fertility, health, and consumption patterns (Smith, 1990). Education, directly and through its impact on occupational status and other aspects of employment history, effects economic well-being at least as strongly after age 65 as before, despite the many life events that may intervene (Crystal et al., 1992). Early on, the women, who found themselves homeless, had to resort to governmental assistance programs to sustain themselves and their families. Moreover, the majority of the elderly women had lived in a lower socioeconomic strata throughout their lives and had not accrued a means for financial security, which resulted in their reliance on public governmental benefit plans. In short, the economic status of both groups reflects the documented curved relationship between age and the percentage of women in poverty, with the greatest risk and occurrence of poverty occurring in the early and late years of life (Barusch, 1994). At all stages in the life cycle, women of color have higher rates of poverty than their white counterparts (Barusch, 1994; Jackson, 1995).

One's income also affects the quality and availability of adequate housing. Extremely low-income households account for one in 10 homeowners, but about one in four renters ("The State of the Nation's Housing," 1998). Disproportionately large shares of these households are single elderly, and single-parent families who are primarily members of ethnic minority groups ("The State of the Nation's Housing," 1998). These are precisely the groups that are most vulnerable to recent changes in public entitlement programs.

Affordability is by far the most pressing problem for low-income renters and homeowners. As of 1995, 5.5 million low-income renter households and 3.8 million owner households were spending more than half their incomes on housing or living in inadequate units ("The State of the Nation's Housing," 1998). To further complicate matters, job growth has shifted to the suburbs resulting in the concentration of poverty in the central part of cities. This shift has added to the fiscal instability of these communities (Duncan \& Brooks-Gunn, 1997). Not only are the poor far removed from the location of job opportunities, they may also have inefficient public transportation to outlining areas where jobs are more plentiful. At the time of the study, none of the younger women were employed. Women in both groups were mobile only to the extent that they could walk or take a bus.

A major feature of the sample was that all the women lived alone. This demographical dimension reflects a significant societal trend. The number of people living alone has steadily increased and is projected to be on the rise in the next decade ("The State of the Nation's Housing," 1998). The average age at first marriage continues to drift upward, and the share of single person households among all cohorts born after 1940 is climbing. The number of single person households aged 65 and over will grow by 1.7 million ("The State of the Nation's Housing," 1998).

The number of single person households among African American women is disproportionately high. For elderly African Americans, the larger number of female-headed households is associated with widowhood, given the disparity in mortality rates between African American women and men (Gibson, 1994). Among younger women, the increase in female-headed households is due primarily to the decreasing propensity to marry during young adulthood. This declining likelihood of marriage is linked to high levels of unemployment and low earnings of a larger percentage of African American men. Also, because of the disproportionate number of African American men who are incarcerated or victims of violent crime, fewer are available to marry, particularly during early adulthood (Blackwell, 1991; Wilkinson, 1993). Moreover, public as- 
sistance program policies have also mitigated against fathers living with their partners and children (Abromowitz, 1993).

That so many reside alone, some by choice and others not, adversely affects the quality of life of many individuals since isolation often results. Individuals who are homeless, are characteristically disaffiliated from usual sources of social support. Although in the pilot study, $63 \%$ of the homeless women were in contact with at least one relative and could call upon someone within their immediate family in case of an emergency, these contacts often were tenuous and fragile. The majority of the elderly women in the sample had a wider range of family and social contacts from which they could draw, and at least $33 \%$ of them were actively involved in church and community activities. Their networks, however, were limited as well.

Not only are there economic ramifications of living alone, there also are health related consequences. Loneliness and disaffiliation are associated with several measures of physical and mental health, including sensory deficits and depression among the elderly (Antonucci, Sherman, \& Vandewater, 1997). For all populations, lack of social support is linked to increased stress (Barrera, 1988). The availability of social support, however, is purported to be a resource which promotes health protection and provides feelings of personal efficacy and a sense of belonging (Barrera, 1988; Taylor, Chatters, \& Jackson, 1997).

The self-reports of the two groups of women regarding their health are colored by the peculiarities of their age and station in life. Conditions reported by the homeless women may have contributed to their becoming homeless, or may have resulted from being homeless, and/or were exacerbated by their living conditions. For example, one young mother who had epilepsy, had to leave a living arrangement with a former partner because her frequent seizures had irreparably strained their relationship. Another woman's asthma worsened after she moved to the shelter. Four of the women were pregnant; one woman was "put out" by a family member when the pregnancy was discovered. The three other women, however, became pregnant during the time they were homeless. Other conditions reported by the younger women were sinusitis, fibroids, depression, alcoholism, or drug use. Sixty-three percent of the homeless women stated they had good health, however, without the benefit of physical findings, the extent to which these were accurate assessments cannot be determined. It has been documented that individuals who are homeless tend to understate and underestimate symptoms of ill health (Ropers \& Boyer, 1987).

In general, the same under-reporting has been found among the elderly as well. Despite the prevalence of chronic disease among older adults, many of them rate their health as excellent or good. The older women in the sample reported hypertension, cataracts, heart disease, cancer, arthritis, back problems, and diabetes. Yet $63 \%$ reported their health as being excellent or good. van Maanen (1988) found that with increasing age, more emphasis is placed on health as a state of mind, even in situations of a failing body. Essentially, if sample members of both age cohorts could go about their daily routines reasonably well, they considered themselves to be in good health. Moreover, both older and younger women of the sample were hindered by access to health care. Three of the homeless women had no health coverage. The majority of the women of both cohorts relied upon either Medicaid or Medicare for their primary health coverage. These health insurance options covered existing illnesses but allowed less for preventive measures. Additionally, the women had limited transportation.

Could the life trajectory that so often leads to persistent poverty be broken for younger women and alleviated for the elderly if the women came together and built upon each other's strengths? African American female-headed families are one of the most impoverished groups in America. The descriptions of both cohorts of women suggest that reinventing or restructuring the extended family for two very vulnerable populations, through mutual linkages, may be a viable option. The complementary nature of the women's perceptions of what "home" is potentially provides further grounds for such a connection. Twentyfive percent of the homeless women merely sought the bare essentials of home, "having a roof over their heads," and actually viewed the shelter as their home. The older women, however, perceived home more symbolically and as an entity through which they could recapture some aspects of relationships and experiences they had lost. A common denomination of the many conceptualizations of "home" is the significance of relationships in a particular environment. Home has distinct properties including order, a source of identity, and a form of connectedness (Franck, 1993). Thus, it is conceivable that an elderly woman living alone in her own house may be "homeless." A woman residing in a shelter, on the other hand, may acquire a "home" by establishing meaningful, sustained bonds with others. Women of the two cohorts could provide a "home" for each other if they were appropriately and adequately supported in their efforts.

The responses of women from both cohorts in favor of coresidential arrangements were consistent with what others have reported about housesharing. Since the nineteenth century, housesharing has been a viable living arrangement (Levinson, 1991; Mantel \& Gildea, 1989). It offers critical benefits that cannot be duplicated by ordinary "low-cost housing" such as the provision of emotional support of parenting, reduction in housing costs through pooling of resources, prevention of isolation, and avoidance of institutionalization-specifically nursing homes for the elderly and foster care placement for the youth (Danigelis \& 
Fengler, 1989; Levinson, 1991). Moreover, the social distance between generations, along with the stereotypes and ill will that often accompany such distance can be diminished (Jaffe, Paivasarat \& Howe, 1994). Housesharing can smooth the transitions that each generation may be simultaneously experiencing: the older person may be undergoing a status passage from independence to dependence, while the younger adult may be moving from dependence to independence (Jaffe, 1989). Since care-taking roles evolve naturally in housesharing, individuals in need of basic health surveillance or maintenance-particularly the elderly-may benefit from the help of a house partner. Through housesharing, safe and secure accommodations could allow occupants to develop a spatial, temporal, and social order to daily life (Dovey, 1986). This would provide individuals with the time, energy, and daily predictability to pursue other activities from job hunting and working to developing and maintaining relationships with others. For young families who are enrolled in the recently established public assistance program, Temporary Assistance to Needy Families (TANF), housesharing may be a bridge to permanent self sufficiency. Housesharing could provide a stable home situation so that children could attend one school, rather than a series of schools. Moreover, mothers and children could be established with a particular health care facility.

Despite the advantages of housesharing, dilemmas such as conflicts in boundary maintenance and exploitation must be considered (M. Hasting, personal communication, November, 1992). Certainly, housesharing would not be an alternative for all poor women who have dire housing needs. For example, women who have substance abuse problems, major mental or physical illnesses, or a history of incarceration, are not likely to be appropriate candidates for housesharing. Moreover, those who simply prefer to live alone are not likely to desire such an arrangement.

\section{IMPLICATIONS AND CONCLUSION}

Linking young homeless women and elderly marginally housed women in coresidential arrangements is an option that nurses, in concert with other disciplines, should further investigate. Encouraging linkages and ensuring that the necessary supports are in place to sustain such arrangements, are means to promote health in both populations. Provided that appropriate screening is done and women have the opportunity to make connections by choice, housesharing could be a viable living arrangement for some. An alliance between the two groups could contribute to strengthening coping strategies, building assets and collective capacity, and promoting community development. All are geared toward edifying and "extending the extended family." Moreover, such linkages could further improve the manner in which health care is provided. Simultaneous offering of health care to more than one generation in a common residential area epitomizes family and community health nursing. Health care and other services administered in this way is empowering, educational, and cost-effective. Moreover, the potential for a stronger articulation between health and housing agencies could be created. Before further contemplation is done, however, more comprehensive examination of the specific needs, preferences, and goals of the women is warranted. In addition, more research is needed to delineate the nature of what supportive efforts are needed to help sustain such linkages.

\section{ACKNOWLEDGEMENTS}

This research was funded by the Office of the Vice President of Research at the University of Michigan. The research assistance of Patricia Nunn and Joan Lynn is appreciated.

\section{REFERENCES}

Abromowitz, M. (1993). Challenging the myths of welfare reform from a woman's perspective. Women and Welfare Reform: Women's Poverty, Women's Opportunities and Women's Welfare (Conference Proceedings). Sponsored by Institute for Women's Policy Research. Held at U.S. House of Representatives, Washington, DC.

Antonucci, T. C., Sherman, A., \& Vandewater, E. (1997). Measures of social support and caregiver burden. Generations, $21,48-51$.

Barrera, M. (1988). Models of social support and life stress: Beyond the buffering hypothesis. In L. Cohen (Ed.), Life events and psychological functioning: Theoretical and methodological issues (pp. 211-236). Beverly Hills, CA: Sage Publications.

Barrow, S., Herman, D., Cordova, P., \& Struening, E. (1999). Mortality among homeless shelter residents in New York City. American Journal of Public Health, 89(4), 529-533.

Barusch, A. (1994). Older women in poverty: Private lives and public policies (pp. 101-123, 169-183). New York: Springer Publishing Companies.

Bernard, H. R. (1994). Research methods in anthropology (pp. 96-101). Thousand Oaks, CA: Sage Publications.

Blackwell, J. (1991). The black community: Diversity and unity (pp. 114-117). New York: Harper Collins.

Crystal, S., \& Shea, D. (1990). Cumulative advantage, cumulative disadvantage and inequality among elderly people. Gerontologist, 30, 437-443.

Crystal, S., Shea, D., \& Krishnaswami, S. (1992). Educational attainment, occupational history, and stratification. Determinants of later life economic outcomes. Journal of Gerontology: Social Sciences, 47, S213-S221.

Danigelis, N., \& Fengler, A. (1989). No place like home: Intergenerational homesharing through social exchange (pp. 3-300). New York: Columbia University Press.

Dovey, K. (1986). Home and homelessness. In J. Altman \& C. M. Werner (Eds.), Home environments (pp. 33-64). New York: Plenum Press. 
Duncan, G. J., \& Brooks-Gunn, J. (1997). Welfare's new rules: A pox on children. Issues in Science and Technology, 14(2), 67-72.

Franck. K. (1993). The meaning and use of housing: Overlooked populations. In E. Arias (Ed.), The meaning and use of housing: International perspectives, approaches, and their applications (pp. 445-456). Avebury, UK: Ashgate Publishing Company.

Gibson, R. C. (1994). The age-by-race gap in health and mortality in the older population. The Gerontologist, 34, 454-462.

Harrison, A. O., Wilson, M. N., Pine, C. J., Chan, S. Q., \& Buriel, R. (1990). Family ecologies of ethnic minority children. Child Development, 61, 347-362.

Hatchett, S. J., Cochran, D. L., \& Jackson, J. S. (1991). Family life. In J. S. Jackson (Ed.), Life in black America (pp. 46-83). Newbury Park, CA: Sage Publications.

Heclo, H. (1988). Generational politics. In J. L. Palmer, T. Smeeding, \& B. B. Torrey (Eds.), The vulnerable (pp. 381-412). Washington, DC: The Urban Institute Press.

Hopper, K., \& Milburn, N. (1996). Homelessness among African Americans: A historical and contemporary perspective. In J. Baumohl (Ed.), Homelessness in America (pp. 123-131). Phoenix, AZ: Oryx Press.

Jackson, J. S. (1995). African American health the life course: A multi-dimensional framework. In P. M. Kato \& I. Mann (Eds.), Health psychology of special populations: Issues of age, gender, and ethnicity (pp. 30-319). New York: Plenum Press.

Jaffe, D. J. (1989). An introduction to elderly shared housing research in the United States. In D. J. Jaffe (Ed.), Shared housing for the elderly (pp. 4-7). New York: Greenwood Press.

Jaffe, D., Pawasarat, A., \& Howe, A. (1994). Care management, equity and efficiency. Age and Aging, 23, 437-443.

Jahiel, R. I. (1992). Preventive approaches to homelessness. In R. I. Jahiel (Ed.), Homelessness: A prevention oriented approach (pp. 11-26). Baltimore, MD: The John Hopkins University Press.

Killion, C. M. (1988). Black, homeless and pregnant. In J. Wang, C. Nath, \& P. Simoni (Eds.), Proceedings of the West Virginia nurses' association research symposium. Nursing: Power through excellence (pp. 259-264). Charleston, WV: West Virginia Nurse's Association Research Conference Group.

Killion, C. M. (1995). Special health care needs of homeless, pregnant women. Advances in Nursing Science, 18, 44-56.

Killion, C. M. (1998). Poverty and procreation among women: An anthropological study with implications for health care providers. Journal of Nurse Midwifery, 43, 273-279.

Leigh, W. A. (1992). Trends in the housing status of black Americans across selected metropolitan areas. In W. A. Leigh \& J. B. Steward (Eds.), The housing status of black Americans (pp. 43-64). New Brunswick, NJ: Transaction Publisher.

Levinson, N. (1991). Share and share alike. Planning, 48, 24-26. van Maanen, H. (1988). Being old does not mean always being sick: Perspectives on conditions of health as perceived by
British \& American elderly. Journal of Advanced Nursing, 13, 701-709.

Mank, A., \& Kaye, L. (1991). Congregate housing for the elderly: Its need, function and perspective. Journal of Housing for the Elderly, 9, 5-20.

Mantell, J., \& Gildea, M. (1989). Elderly shared housing in the United States. In D. Jaffe (Ed.), Shared housing for the elderly (pp. 13-23). New York: Greenwood Press.

Mills, C., \& Ota, H. (1989). Homeless women with minor children in the Detroit metropolitan area. Social Work, 53, 485-487.

Patton, M. Q. (1990). Qualitative evaluation and research method (pp. 169-183). Newbury Park, CA: Sage Publications.

Preventing homelessness. (1991). Shelterforce, 13(6), 12-16.

Rich, E. (1995). Labels and social contest. In D. Rich, T. Rich, \& L. Mullins (Eds.), Old and homeless-Double jeopardy (pp. 1-5). Westport, CT: Auburn House.

Ropers, R., \& Boyer, R. (1987). Perceived health status among the new urban homeless. Social Science and Medicine, 24, 669-678.

Select Committee on Aging, House of Representatives. (1989). The quality of life for older women. Older women living alone. Washington, DC: U.S. Government Printing Office.

Smith, M. (1990). What is new in "New Structuralist" analyses of earnings? American Sociological Review, 55, 827-841.

Solmon, L. (1975). The relation between schooling and savings behavior: An example of the indirect effects of education. In T. Juster (Ed.), Education, income and human behavior (pp. 253-293). New York: Academic Press.

Stack, C. (1974). All our kin: Strategies for survival in a black community (pp. 22-31, 124-129). New York: Harper \& Row.

Stark, L. R. (1992). Demographics and stereotypes of homeless people. In R. I. Jahiel (Ed.), Homelessness: A preventionoriented approach (pp. 27-39). Baltimore, MD: The Johns Hopkins University Press.

Taylor, J. T., Chatters, L. M., \& Jackson, J. S. (1997). Changes over time in support network involvement among black Americans. In R. J. Taylor, J. S. Jackson, \& L. M. Chatters (Eds.), Family life in black America (pp. 293-316). Thousand Oaks, CA: Sage Publications.

The state of the Nation's housing. (1998). Cambridge, MA: Joint Center for Housing Studies at Harvard University.

U.S. Bureau of the Census. (1990). Social and economic characteristics, cp-2-24 (p. 1005). Washington, DC: U.S. Government Printing.

U.S. Conference of Mayors. (1993). Ending homelessness in America's cities: Implementing a plan of action. San Francisco: Home Base.

Wagner, J. D., \& Menke, E. M. (1992). Case management of homeless families. Clinical Nurse Specialist, 6, 65-71.

Weber, R. P. (1995). Basic content analysis (pp. 44-53). Beverly Hills, CA: Sage Publications.

Wilkinson, D. (1993). Family ethnicity in America. In H. McAdoo (Ed.), Family ethnicity in America (pp. 15-59). Newbury Park, CA: Sage Publications. 